OPEN ACCESS

Edited by:

Charles De Bock,

Children's Cancer Institute, Australia

Reviewed by:

Rick F. Thorne,

The University of Newcastle, Australia

Michael Diamantidis,

University Hospital of Larissa, Greece

*Correspondence:

Hanne Vibeke Marquart hanne.marquart@regionh.dk

Claus Christensen

claus.rene.lykke.christensen@ regionh.dk

Specialty section: This article was submitted to Hematologic Malignancies, a section of the journa

Frontiers in Oncology

Received: 04 March 2020

Accepted: 21 April 2020

Published: 22 May 2020

Citation:

Scharff BFSS, Modvig S, Marquart HV and Christensen C (2020) Integrin-Mediated Adhesion and Chemoresistance of Acute

Lymphoblastic Leukemia Cells Residing in the Bone Marrow or the Central Nervous System.

Front. Oncol. 10:775

doi: 10.3389/fonc.2020.00775

\section{Integrin-Mediated Adhesion and Chemoresistance of Acute Lymphoblastic Leukemia Cells Residing in the Bone Marrow or the Central Nervous System}

\author{
Bibi Fatima Syed Shah Scharff, Signe Modvig, Hanne Vibeke Marquart* and \\ Claus Christensen*
}

Department of Clinical Immunology, Copenhagen University Hospital Rigshospitalet, Copenhagen, Denmark

Acute Lymphoblastic Leukemia (ALL) is the most common cancer in childhood. Despite a significantly improved prognosis over the last decade with a 5-years survival rate of $\sim 90 \%$, treatment-related morbidity remains substantial and relapse occurs in 10-15\% of patients (1). The most common site of relapse is the bone marrow, but early colonization and subsequent reoccurrence of the disease in the central nervous system (CNS) also occurs. Integrins are a family of cell surface molecules with a longstanding history in cancer cell adherence, migration and metastasis. In chronic lymphoblastic leukemia (CLL), the VLA-4 integrin has been acknowledged as a prognostic marker and mounting evidence indicates that this and other integrins may also play a role in acute leukemia, including ALL. Importantly, integrins engage in anti-apoptotic signaling when binding extracellular molecules that are enriched in the bone marrow and CNS microenvironments. Here, we review the current evidence for a role of integrins in the adherence of ALL cells within the bone marrow and their colonization of the CNS, with particular emphasis on mechanisms adding to cancer cell survival and chemoresistance.

\section{Keywords: acute lymphoblastic leukemia, integrins, chemoresistance, CNS, bone marrow}

\section{INTRODUCTION}

Integrins comprise a family of heterodimeric cell adhesion receptors, each composed of one alpha and one beta subunit. In hematopoietic and epithelial cells, integrin adhesion to stromal cells or extracellular matrix (ECM) components induces signaling essential for cell survival, proliferation and migration. Integrins are also vital to cancer cells, that exploit the integrins to favor their own survival, invasion and migration within tissues, endothelial cell binding, extravasation and metastatic colonization of distal organs (2). In hematological cancers, expression of integrin $\alpha 7$ was shown to be associated with acute myelogenous leukemia (AML) with granulocytic sarcoma (3) and integrin $\alpha 4: \beta 1$ (VLA-4) is an independent prognostic factor in chronic lymphoblastic leukemia (CLL) (4) and has been associated with chemoresistance in CLL, multiple myeloma, AML and acute lymphoblastic leukemia (ALL) (5-7). Thus, integrin-mediated chemoresistance is perceived as a form of adhesion-mediated drug resistance (CAM-DR) (8). 
ALL is a malignant disorder of lymphoid progenitor B- or $\mathrm{T}$-cells, representing the most common form of pediatric cancer (patients $<15$ years of age) (9). ALL is largely a bone marrow (BM) disease and thus diagnosis and treatment stratification using disease monitoring by minimal residual disease (MRD) (10), are done optimally in BM samples. BM constitutes the most frequent site of relapse (11) and has been proposed as a protective niche for ALL (12). In addition, ALL has a marked tendency to disseminate to the central nervous system (CNS) and survive therapy. At the time of diagnosis, $8-13 \%$ of ALL patients have measurable leukemic blasts within the CNS (13-15) and despite of the CNS prophylaxis in current treatment protocols, 10-30\% of relapses involve the CNS (16-18).

At present, several integrins have been proposed as likely contributors to CAM-DR in ALL and different routes of dissemination from BM to the CNS have been suggested $(19,20)$. Here, we review the current evidence linking individual integrins to the adherence and chemoresistance of ALL cells within the BM and their dissemination to CNS.

\section{INTEGRIN STRUCTURE AND SIGNALING}

In humans, 18 alpha subunits and 8 beta subunits are known, which assemble into 24 different heterodimers. Of these, only half have been identified in immune cells $(21,22)$. Each integrin consists of a large ectodomain responsible for ligand binding, a transmembrane domain, and an intracellular domain making contacts with the cytoskeleton. Integrins differ considerably with respect to ligand specificity. For example, $\alpha 6: \beta 1$ only binds laminin (23) whereas $\alpha 4: \beta 1$ (VLA-4) can bind the ECM molecules fibronectin, thrombospondin, and osteopontin as well as the cell surface molecules vascular cell adhesion molecule 1 (VCAM-1) and mucosal addressin cell adhesion molecule 1 (MadCAM-1) (21, 24). Today, integrin subunits may be referred to according to the $\mathrm{CD}$ (Cluster of Differentiation) nomenclature and integrin dimers may be named according to the scheme $\alpha: \beta$ or as very late antigens (VLA) in the case of dimers containing $\beta 1$. Previous reviews by Bertoni et al. and Humphries et al. serve as convenient sources of information on integrin nomenclature and binding partners $(21,24)$.

Integrins adopt different conformations with distinct ligandbinding affinities. The shift to the extended-open conformation allows for high-affinity ligand binding and constitutes integrin activation (25). This may be achieved via "inside-out" signaling, i.e., intracellular signals received from other receptors or tensile forces acting on the integrin heterodimers through their cytoskeletal connections. Alternatively, activation may arise from "outside-in" signaling through ligand-binding or mechanical forces (26), conferred by e.g., blood- or cerebrospinal fluid (CSF) flow. The latter may induce so-called catch-bonds, which prolongs bond lifetime and allows for more stable adhesion. It plays a role in $\alpha \mathrm{L}: \beta 2$ integrin-mediated adhesion to ICAM1 during leukocyte arrest on the inner side of inflamed blood vessels (27-29).

When binding ECM molecules, integrins initiate reorganization of these molecules and undergo clustering on the plasma membrane. In the case of $\alpha 5: \beta 1$ binding to fibronectin, clustering of integrins leads to the assembly of fibronectin molecules into larger insoluble fibrils (30). Coinciding with the clustering, multiprotein complexes form on the cytoplasmic side, which serve as a hub for outside-in signaling (31). In general, outside-in signaling commences with recruitment and activation of the non-receptor tyrosine kinases focal adhesion kinase (FAK) and the Src kinase, or alternatively the FAK-related kinase PYK2 and the spleen tyrosine kinase (SYK) $(32,33)$. Subsequently, these kinases activate multiple pathways involving MEK-MAPK/ERK, PI3K-AKT, JAK-STAT, mTOR, and NFkB proteins (34) thereby affecting a range of cell fate decisions including cell cycle progression $(35,36)$ and survival vs. apoptosis $(37,38)$. Interestingly, integrin dynamics involves a continuous recycling of transmembrane integrins to the cytoplasm and FAK kinase remains active when associated with integrins in endosomal membranes. This mechanism contributes to the survival of metastasizing breast cancer cells (39) and could explain how integrins mediate survival signaling also in circulating leukemic blasts.

The ability of outside-in signaling to suppress the apoptotic response is of key importance in integrin-mediated chemoresistance. Many of the agents used as first-line cancer therapeutics, incl. the ALL induction therapy drugs doxorubicine/adriamycin and vincristine, are strong inducers of DNA damage, causing cancer cell elimination by triggering apoptosis $(40,41)$. Across different cancer types, MAPK/ERK and PI3K-AKT signaling have been shown to increase drug resistance via altered expression of Bcl-2 family proteins $(42,43)$ or increased activity of the ATP-binding cassette C 1 (ABCC1) transporter/multidrug resistance-associated protein 1 (MDR1) $(44,45)$. In accordance, the binding of $\alpha 2: \beta 1$ integrin to collagen I has been shown to promote resistance to doxorubicine in Jurkat T-ALL cells by activating ERK and maintaining high levels of the anti-apoptotic Bcl-2 protein Mcl-1 (46) or upregulating ABCC1/MRP-1 (47). Furthermore, activation of integrin $\beta 1$ by different ECM molecules initiated RAFTK/PYK2-AKT signaling and increased chemoresistance in different leukemic cell lines $(48,49)$, which was linked to the activation of the ABCC1/MRP-1 (50). In addition, AKT can promote survival signaling along several pathways, e.g., via the mTOR kinase and NFkB and STAT transcription factors (51-55).

The above-mentioned studies show that the interaction between integrins and ECM ligands activates pro-survival pathways that are shared by cancer cells across type. However, some studies suggest more unorthodox mechanisms. Jacamo et al. used an ectopic BM model in mice and described how drug resistance in leukemic cells depended on VLA-4:VCAM1mediated NFkB activation in stromal cells (56) whereas, Polak et al. showed integrin-dependent cell-cell signaling through tunneling nanotubes between BCP-ALL cells and mesenchymal stromal cells, inducing pro-survival cytokine secretion and prednisolone resistance (57). Another study found that integrin $\beta 1$ existed in a multi-protein membrane complex together with the potassium channel protein hERG1 (human Ether-à-go-goRelated-Gene 1) and the $\mathrm{C}-\mathrm{X}-\mathrm{C}$ chemokine receptor type 4 (CXCR4) and that stromal cell-mediated chemoresistance in 
TABLE 1 | Important works demonstrating roles or associations of integrins with chemoresistance, tissue localization or clinical outcome.

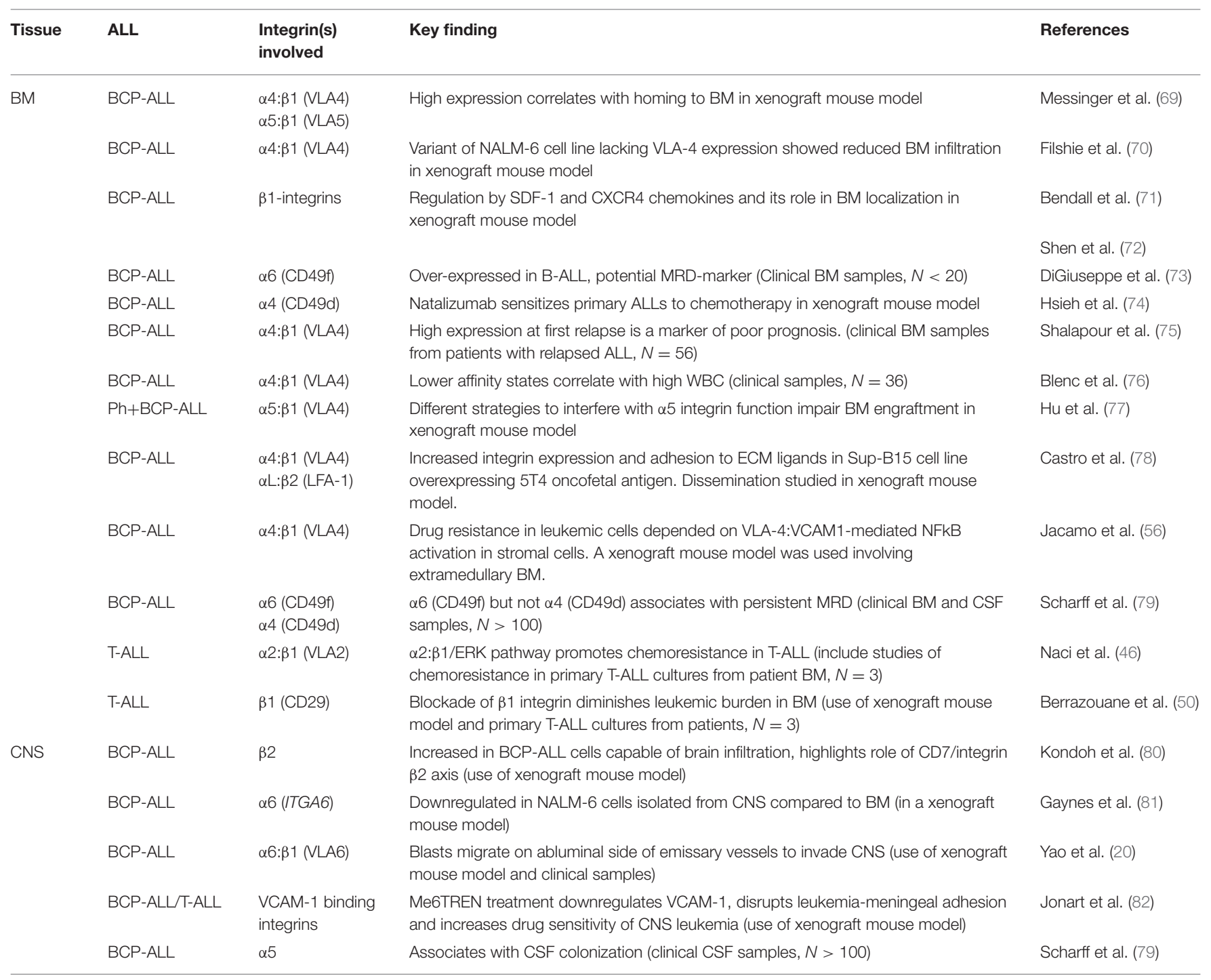

Listed are only clinical studies involving patient samples or preclinical studies involving the study of human leukemic cells in xenograft mouse models. Preclinical studies only focusing on leukemic cell lines in vitro are described in the text.

ALL cells was overcome by hERG1 blockade or inhibition of the CXCR4/CXCL12 axis (58). Finally, in various non-leukemic tumor models, $\beta 1$ integrin binds the proto-oncogenic receptor c-Met whereby it contributes to sustained pro-survival signaling from this receptor in a manner that appears to be independent of ECM ligands $(59,60)$.

\section{ADHESION AND CHEMORESISTANCE OF ALL WITHIN THE BONE MARROW}

In healthy $\mathrm{BM}$, the localization of hematopoietic stem cells (HSCs) is highly influenced by the microenvironment, including chemokines/cytokines, extracellular matrix proteins and cell surface proteins within both the endosteal and vascular niches. Notably, the endosteal niche is rich in fibronectin and collagen type I (61) whereas laminin and collagen type IV are enriched within the vascular niche (62). Not surprisingly, integrins binding these ECM molecules are expressed on $\mathrm{CD}_{3} 4^{+}$stem cells and essential for sustaining hematopoiesis (63). In vivo experiments including gene ablation and function blocking antibodies indicate that $\beta 1$-containing integrins are particularly important and emphasize roles of both $\alpha 4$ and $\alpha 6$ (64-67).

In leukemias, cellular proliferation, maturation, adhesion and migration are dysregulated leading to high numbers of premature, malignant cells in the BM as well as in the blood. As for normal hematopoiesis, the homing, survival and egression of leukemic blasts are largely controlled by the microenvironment of the BM and an important role is afforded to the integrin family (68). Table 1 summarizes the most important studies showing integrin-mediated adhesion or chemoresistance in ALL. Overall, studies have pointed to the importance of BM stromal cells in 
the survival of BCP-ALL cells and the role played by integrins in this interaction $(83,84)$. In SCID mice, both $\alpha 4: \beta 1$ and $\alpha 5: \beta 1$ have been shown to be important for binding of patient-derived BCP-ALL cells to BM stromal cells (69) and in patients, lower affinity states of $\alpha 4: \beta 1$ on BCP-ALL cells appear to correlate with higher numbers of blasts in circulation, i.e., white blood cell count (WBC) (76). The latter suggests that the retainment of blasts within the BM is largely dictated by $\alpha 4: \beta 1$-mediated adhesion in agreement with studies of hematopoietic stem cells $(85,86)$.

Shalapour et al. studied 56 BCP-ALL patients with BM relapse and correlated the expression of $\alpha 4: \beta 1$ in $B M$ samples with clinical outcome. They found that high $\alpha 4: \beta 1$ expression associated with shorter event-free and overall survival (75). Later, Hsieh et al. studied 207 cases of BCP-ALL with detectable MRD at end of induction, confirming a poorer outcome for patients showing high compared to low integrin $\alpha 4$ expression. Furthermore, they provided strong evidence for the chemoprotective function of integrin $\alpha 4$ showing that drug resistance of BCP-ALL in vivo was overcome by either ITGA4 gene knock-out or $\alpha 4$ blockade using the humanized anti- $\alpha 4$ monoclonal antibody natalizumab (74). Natalizumab inhibits both members of the $\alpha 4$ integrin family, $\alpha 4: \beta 1$ and $\alpha 4: \beta 7$, whereas the small non-peptidic molecule inhibitor TBC3486 is 200-fold more potent toward $\alpha 4: \beta 1$ than $\alpha 4: \beta 7$. Using this inhibitor, Hsieh et al. was able to show that the chemoresistant phenotype of ALL was mainly due to $\alpha 4: \beta 1$ (87).

Apart from $\alpha 4: \beta 1$, reports also point to chemoprotective roles of other integrins. In Philadelphia chromosome positive ALL $\left(\mathrm{Ph}^{+}\right.$-ALL), inhibition or knock-down of $\alpha 5$ reduced the leukemic engraftment of BM in NOD/SCID gamma (NSG) mice and reduced the survival of leukemic cells treated with tyrosine kinase inhibitors (77). It is noteworthy, that altered integrin expression patterns have been reported in different types of cancers and in some cases contradictory data for the same integrin are found within the same cancer type (2). A recent study investigating the mRNA and protein surface expression of integrins in ALL failed to confirm the proposed association between MRD and $\alpha 4 / C D 49 \mathrm{~d}$ or $\alpha 5$ mRNA in a large patient group. The strongest association with MRD was instead found for $\alpha 6 / C D 49 f(79)$. The reason for these discrepancies is currently unknown. However, integrin regulation is highly complex and what defines integrin function is integrin activation and the resulting ligand affinity of specific integrin heterodimers, rather than the levels of individual integrin subunits per se. Hence, studies addressing affinity states of $\alpha 4: \beta 1$, such as the work of Shalapour et al. (75) are likely closer to revealing the association of $\alpha 4: \beta 1$ with MRD than studies based entirely on expression profiles, such as the work of Scharff et al. Also, the work of Scharff et al. did not specifically address $\mathrm{Ph}^{+}$ALL, which may be the reason why an association between MRD and $\alpha 5$ was not seen (79).

\section{ADHESION AND CHEMORESISTANCE OF ALL WITHIN THE CNS}

The CNS is an immunologically privileged site to which access is limited by the blood-brain barrier (BBB) and the blood-cerebrospinal fluid barrier (BCSFB). The BBB is composed of the endothelial cell (EC) lining and the EC basement membrane of CNS microvessels plus a second underlying parenchymal basement membrane, which is formed by astrocytes and part of the glia limitans. At the level of CNS capillaries, the glia limitans and the EC basement membrane form a composite layer; whereas at the level of post-capillary venules the two layers are separated by a CSF-filled perivascular space that fuses with the leptomeningeal/subarachnoid space (88). In contrast, the BCSFB exists at the choroid plexus (CP), comprising villous structures bulging from the walls in certain parts of the four ventricles of the brain. The outer layer consists of specialized epithelial cells, known as ependymal cells, that are interconnected by tight junctions and underneath, an extensive network of microcapillaries exists composed of fenestrated endothelial cells (89).

As part of immunosurveillance of the CNS, normal immune cells cross the BCSFB but generally remain in the CSF. In healthy individuals, these immune cells are predominantly central memory $\mathrm{CD} 4^{+}$cells (90). However, in response to antigens and ensuing neuroinflammation, proinflammatory cytokines alter the microvessels allowing passage of the $\mathrm{BBB}$ at the site of the post-capillary venules by both $\mathrm{T}$ cells and myeloid cells $(91,92)$. Integrins appear to be involved in the trafficking of normal immune cells across the brain barriers during neuroinflammation. Hence, in multiple sclerosis (MS) patients, the $\alpha 4$-inhibitor natalizumab reduced the number of $\mathrm{CD}^{+}$cells in CSF (93) as well as relapse frequency (94), and in assays that use immune cells from MS patients, natalizumab blocked the transmigration across layers mimicking BBB (93). These studies suggest that $\alpha 4$-containing integrins, e.g., $\alpha 4: \beta 1$ or $\alpha 4: \beta 7$, are involved in the transmigration process across the $\mathrm{BBB}$ and/or BCSFB. With respect to crossing the BCSFB, VCAM-1 binding on the basolateral side is less likely, as it is not expressed by endothelial cells of the CP (95) and although expressed in CP ependymal cells, it is primarily localized to the villi on the apical side of these cells (96).

ALL has a marked tendency to disseminate to the CNS with T-ALL showing a higher incidence of CNS relapse than BCPALL $(13,17)$. Contrary to solid cancer metastatic cells, which invade the brain parenchyma, disseminated ALL is typically isolated to the leptomeninges. Early studies demonstrated that of 126 brains from autopsied leukemia patients, $42 \%$ had leukemic infiltration confined to the superficial/perivascular arachnoid while only $13 \%$ had signs of leukemic blasts within the brain parenchyma (97). Later studies, using xenograft mouse models, have shown that the ability to enter the CNS is a generic property of human ALL and not the result of rare selection of particular clones. It is difficult to ascertain the degree to which mouse-man differences contribute to the outcome of such xenotransplantation experiments. However, the histopathology accompanying the studies by Williams et al. showed striking similarities to the findings in patients, including leukemic infiltration around the dural venous sinuses (Figure 1A) and CP but not of brain parenchyma (19). Collectively, these data argue that leukemic blasts primarily transit the BCSFB rather than the $\mathrm{BBB}$, similar to normal immune cells during immune surveillance in healthy brains (Figure 1B). In vitro culture 
A

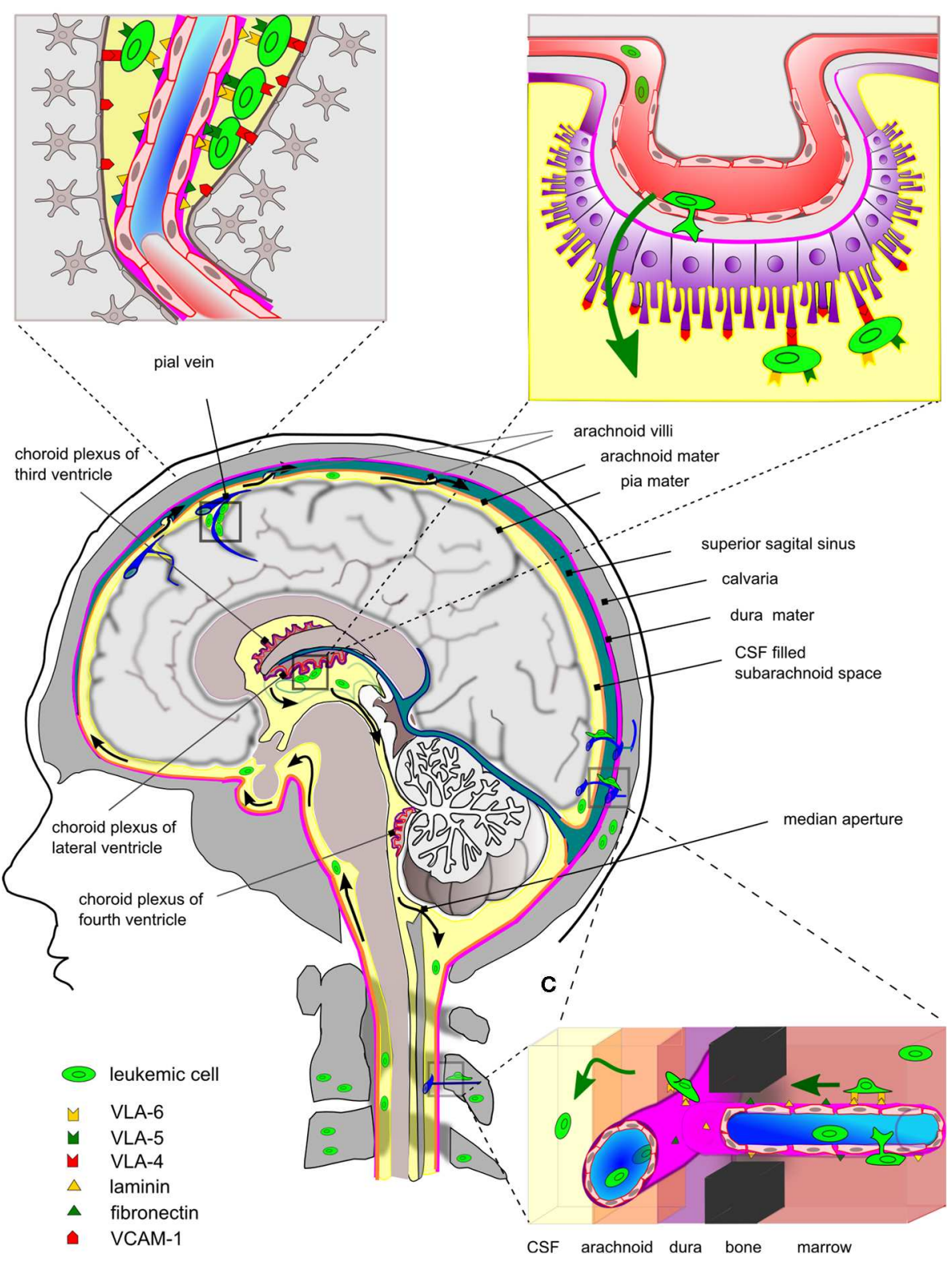

FIGURE 1 | Entry routes and localization of ALL cells within the CNS. Simplistic drawing highlighting main entry routes and localization of ALL cells within the central nervous system and the proposed contribution of specific integrin-ligand interactions. (A) Leukemic cells are commonly found within the superficial arachnoid or seen pinched in the perivascular space around the post-capillary venules. At these sites, integrins may be involved in the binding to basal membrane proteins or VCAM-1 expressed by astrocytic feet processes. (B) The blood-cerebrospinal fluid barrier (BCSFB) is located at the choroid plexus (CP) located in the brain ventricles. The BCSFB is proposed as a main entry site for ALL cells into the CSF. The ALL cells in BM egress to peripheral blood circulation and subsequently arrive at microvessels underneath the CP, cross the layers of fenestrated endothelium and CP epithelial cells and can be seen adhering to VCAM-1 positive villi on the apical side. The latter suggests the involvement of integrins, such as VLA-4 ( $\alpha 4: \beta 1)$. (C) Leukemic cells in the skull/vertebral bone marrow may migrate on the abluminal side of the endothelial cells of small vessels, thereby traversing through channels in compact bone and subsequently enter the meningeal space. This process may involve integrins binding basal membrane proteins as found for integrin $\alpha 6$ binding to laminin. For clarity, the drawing is disproportionate and anatomical details have been omitted. Black arrows indicate flow of CSF and green arrows indicate movement of leukemic blasts.

models mimicking BCSFB have been developed based on rodent CP epithelial cells immortalized by SV40 large T antigen and immortalized CP epithelial cells from a human papilloma patient.
Using such models, it was formally demonstrated that T-ALL and BCP-ALL cell lines can cross monolayers of CP epithelial cells in response to CSF-borne chemokines (98-100). In contrast, 
investigations of leukemic transmigration across BBB suggest that this form of crossing requires expression of particular adhesion molecules, not ubiquitously expressed by ALL cells (101), and only occurs secondary to endothelial activation by factors secreted from leukemic blasts or treatment-related neurotoxicity $(102,103)$.

As for normal lymphocytes (21), leukemic cells express most if not all integrins $(79,104)$. This provides ample possibilities for adhesion to the basal membranes of EC as well as ICAMs and VCAM-1 expressed on the surface of astrocytic foot processes (105), when leukemic cells are pinched in the perivascular space of post-capillary venules (Figure 1A). In addition, the integrin repertoire of leukemic cells would also allow adhesion to ICAMs and VCAM-1 on the apical side of the CP epithelial cells after traversing the BCSFB (96) (Figure 1B). Recently, Yao et al. proposed a non-hematogenous route into the CNS where leukemic blasts use integrin $\alpha 6$ to migrate on the laminin that is part of basal membranes on the abluminal site of emissary vessels (20) (Figure 1C). Such vessels connect vertebral or calvarial $\mathrm{BM}$ and the subarachnoid space of the spine and brain, respectively, and represent pathways employed by neural progenitors during neural development $(106,107)$. Yao et al. used a xenograft model based on Nalm- 6 cells and primary human ALL cells combined with detailed histological examination and intravital fluorescent microscopy to provide compelling evidence for the migration of leukemic blasts on the outside of vessels. Their focus on integrin $\alpha 6$ resulted from the use of the PI3K $\delta$ inhibitor GS-649443, which not only reduced CNS involvement in their xenograft model but also caused a reduction in ITGA6 mRNA levels (20). However, blocking antibodies to $\alpha 6$ reduced but did not abolish CSF involvement in Nalm-6 engrafted mice (20) and therefore, the question remains whether $\alpha 6$ is actually alone in facilitating this form of non-hematogenous dissemination. In the work by Scharff et al., dissemination of BCP-ALL to the CSF was negatively correlated to surface $\alpha 6 / C D 49 f$ in clear contradiction of the results of Yao et al. Instead, a significant association was found between blasts in CSF and ITGA5 mRNA levels (79). Possibly, man-mouse differences could explain different outcomes in the mouse xenograft model used by Yao et al. and patient material investigated by Scharff et al. Furthermore, the latter work correlated the blast count in CSF with the leukemic integrin expression in BM samples, which may have overlooked subpopulations of ITGA6-expressing blasts that are actively engaged in adhesion and migration on the abluminal side of vessels connecting BM and CNS. With respect to ITGA5, functional studies are warranted to determine whether ALL blasts employ $\alpha 5: \beta 1$ to migrate on the outside of vessels as proposed by Yao et al. (20).

Only few studies have addressed the role of the CNS microenvironment in conferring chemoresistance to leukemic cells and its link to integrin expression. Akers et al. used co-culture models to show that astrocytes, $\mathrm{CP}$ epithelial cells and meningeal cells increased the resistance of four ALL cell lines to cytarabine, dexamethasone and methotrexate commonly included in prophylactic regimens (108). Similarly, Gaynes et al. (81) found that CP epithelial cells conferred resistance to Nalm-6 cells to cytarabine and methotrexate. Of note, this study also investigated the differential impact of CNS and $\mathrm{BM}$ microenvironments on the transcriptome, finding that ITGA6 was downregulated in Nalm-6 cells isolated from CNS compared to BM (81). The latter argues against the role of integrin $\alpha 6 / C D 49 f$ in facilitating the CNS involvement proposed by the work of Yao et al. (20), also based on Nalm-6 cells (20). The transcriptomic profile provided by the Gaynes et al. highlights the impact of microenvironment on the expression of integrins. Furthermore, the recent work of Jonart et al. showed that reducing leukemia-meningeal adhesion with Me6TREN (Tris[2-(dimethylamino)ethyl] amine) not only reduced leukemia chemoresistance but also the expression levels of several genes including VCAM-1 (82). Since the expression levels of integrins and their ligands are influenced by microenvironment and adhesion, caution is warranted in the interpretation of expression studies associating expression of integrins with chemoresistance or tissue distribution.

\section{PERSPECTIVES}

Although the current therapeutic regimens in ALL yield a 5 -years overall survival of around $90 \%, 10-15 \%$ of patients continue to experience relapse (1). As illustrated in this review, compelling evidence exists for key roles of integrins in ALL cell survival, chemoresistance and CNS colonization, albeit clinical studies of integrins as therapeutic targets in ALL, and CNS involvement in particular, remain scarce. A wide variety of anti-integrin drugs are in clinical evaluation, among which a few are in clinical use for other diseases (8, 109), but at present, no integrin-targeted drugs have entered clinical trials in the treatment of CNS disseminated ALL. The integrin $\alpha 4$-inhibitor Natalizumab, has shown promising effect on ALL survival in mouse models in combination with chemotherapy $(74,87)$, but even though Natalizumab is known to prevent immune cell entry into the CNS in multiple sclerosis (94), it remains unclear whether it could also reduce CNS relapse frequency in ALL. Moreover, the risk of progressive multifocal leukoencephalopathy makes the compound potentially unsuitable for ALL patients (110). In general, integrins play important roles in normal immune cell functions, both inside and outside the CNS, making the risk of side effects of integrin-targeted therapy a real concern. Accordingly, further studies on the therapeutic role of integrins in ALL with CNS colonization are warranted.

In particular, ALL entry routes into the CNS need to be further elucidated. Recent, intriguing studies have suggested direct ALL/immune cell entry from calvarial bone marrow to the subarachnoid space along small vessels penetrating compact skull bone $(20,111)$, through specific interactions of adhesion molecules (20) and possibly driven by chemotactic signals (112). In support of this concept are post-mortem studies of ALL patients showing the meninges as a predilection site for ALL cells (97), as well as studies showing calvarial BM involvement as a frequent feature in ALL (113), but there is a clear need for further evidence on this matter. Unraveling such details of 
ALL cell CNS-entry mechanisms is a prerequisite for accurate and effective targeting of the integrins involved as a possible addition to the standard CNS prophylaxis in order to prevent CNS involvement and relapse of ALL.

\section{REFERENCES}

1. Toft N, Birgens H, Abrahamsson J, Bernell P, Griškevičius L, Hallböök H, et al. Risk group assignment differs for children and adults 1-45 yr with acute lymphoblastic leukemia treated by the NOPHO ALL-2008 protocol. Eur J Haematol. (2013) 90:404-12. doi: 10.1111/ejh.12097

2. Hamidi H, Ivaska J. Every step of the way: integrins in cancer progression and metastasis. Nat Rev Cancer. (2018) 18:533-48. doi: $10.1038 /$ s41568-018-0038-z

3. Kobayashi N, Oda T, Takizawa M, Ishizaki T, Tsukamoto N, Yokohama A, et al. Integrin $\alpha 7$ and extracellular matrix laminin 211 interaction promotes proliferation of acute myeloid leukemia cells and is associated with granulocytic sarcoma. Cancers (Basel). (2020) 12:1-15. doi: $10.3390 /$ cancers 12020363

4. Dal Bo M, Bulian P, Bomben R, Zucchetto A, Rossi FM, Pozzo F, et al. CD49d prevails over the novel recurrent mutations as independent prognosticator of overall survival in chronic lymphocytic leukemia. Leukemia. (2016) 30:20118. doi: 10.1038/leu.2016.88

5. de la Fuente MT, Casanova B, Cantero E, Hernández del Cerro M, GarciaMarco J, Silva A, et al. Involvement of p53 in alpha4betal integrin-mediated resistance of B-CLL cells to fludarabine. Biochem Biophys Res Commun. (2003) 311:708-12. doi: 10.1016/j.bbrc.2003.10.054

6. Matsunaga T, Takemoto N, Sato T, Takimoto R, Tanaka I, Fujimi A, et al. Interaction between leukemic-cell VLA-4 and stromal fibronectin is a decisive factor for minimal residual disease of acute myelogenous leukemia. Nat Med. (2003) 9:1158-65. doi: 10.1038/nm909

7. Damiano JS, Cress AE, Hazlehurst LA, Shtil AA, Dalton WS. Cell adhesion mediated drug resistance (CAM-DR): role of integrins and resistance to apoptosis in human myeloma cell lines. Blood. (1999) 93:1658-67. doi: 10.1182/blood.V93.5.1658.405a19_1658_1667

8. Shishido S, Bönig H, Kim Y-M. Role of integrin alpha4 in drug resistance of leukemia. Front Oncol. (2014) 4:99. doi: 10.3389/fonc.2014.00099

9. Greaves M. A causal mechanism for childhood acute lymphoblastic leukaemia. Nat Rev Cancer. (2018) 18:471-84. doi: 10.1038/s41568-018-0015-6

10. Coustan-Smith E, Sancho J, Hancock ML, Boyett JM, Behm FG, Raimondi SC, et al. Clinical importance of minimal residual disease in childhood acute lymphoblastic leukemia. Blood. (2000) 96:2691-6. doi: 10.1182/blood.V96.8.2691.h8002691_2691_2696

11. Gaynon PS, Qu RP, Chappell RJ, Willoughby ML, Tubergen DG, Steinherz PG, et al. Survival after relapse in childhood acute lymphoblastic leukemia: impact of site and time to first relapse-the Children's Cancer Group experience. Cancer. (1998) 82:1387-95. doi: 10.1002/(SICI)10970142(19980401)82:7<1387::AID-CNCR24>3.0.CO;2-1

12. Bradstock KF, Gottlieb DJ. Interaction of acute leukemia cells with the bone marrow microenvironment: Implications for control of minimal residual disease. Leuk Lymphoma. (1995) 18:1-16. doi: 10.3109/10428199509064917

13. Lazarus HM, Richards SM, Chopra R, Litzow MR, Burnett AK, Wiernik $\mathrm{PH}$, et al. Central nervous system involvement in adult acute lymphoblastic leukemia at diagnosis: results from the international ALL trial MRC UKALL XII/ECOG E2993. Blood. (2006) 108:465-72. doi: 10.1182/blood-2005-11-4666

14. Levinsen M, Marquart H V., Groth-Pedersen L, Abrahamsson J, Albertsen $\mathrm{BK}$, Andersen MK, et al. Leukemic blasts are present at low levels in spinal fluid in one-third of childhood acute lymphoblastic leukemia cases. Pediatr Blood Cancer. (2016) 63:1935-42. doi: 10.1002/pbc.26128

15. Thastrup M, Vibeke H, Mette M, Kathrine L, Abrahamsson J, Klug B, et al. Flow cytometric detection of leukemic blasts in cerebrospinal fl uid predicts risk of relapse in childhood acute lymphoblastic leukemia: a Nordic Society

\section{AUTHOR CONTRIBUTIONS}

All authors listed have made a substantial, direct and intellectual contribution to the work, and approved it for publication.

of Pediatric Hematology and Oncology study. Leukemia. (2020) 34:336-46. doi: 10.1038/s41375-019-0570-1

16. Cortes J. Central nervous system involvement in adult acute lymphocytic leukemia. Hematol Oncol Clin North Am. (2001) 15:145-62. doi: 10.1016/S0889-8588(05)70203-3

17. Martínez-Laperche C, Gómez-García AM, Lassaletta Á, Moscardó C, Vivanco JL, Molina J, et al. Detection of occult cerebrospinal fluid involvement during maintenance therapy identifies a group of children with acute lymphoblastic leukemia at high risk for relapse. Am J Hematol. (2013) 88:359-64. doi: 10.1002/ajh.23407

18. Krishnan S, Wade R, Moorman A V., Mitchell C, Kinsey SE, Eden TOB, et al. Temporal changes in the incidence and pattern of central nervous system relapses in children with acute lymphoblastic leukaemia treated on four consecutive Medical Research Council trials, 1985-2001. Leukemia. (2010) 24:450-9. doi: 10.1038/leu.2009.264

19. Williams MTS, Yousafzai YM, Elder A, Rehe K, Bomken S, FrishmanLevy L, et al. The ability to cross the blood-cerebrospinal fluid barrier is a generic property of acute lymphoblastic leukemia blasts. Blood. (2016) 127:1998-2006. doi: 10.1182/blood-2015-08-665034

20. Yao H, Price TT, Cantelli G, Ngo B, Warner MJ, Olivere L, et al. Leukaemia hijacks a neural mechanism to invade the central nervous system. Nature. (2018) 560:55-60. doi: 10.1038/s41586-018-0342-5

21. Bertoni A, Alabiso O, Galetto AS, Baldanzi G. Integrins in T cell physiology. Int J Mol Sci. (2018) 19:485. doi: 10.3390/ijms19020485

22. Zhang $\mathrm{Y}$, Wang $\mathrm{H}$. Integrin signalling and function in immune cells. Immunology. (2012) 135:268-75. doi: 10.1111/j.1365-2567.2011.03549.x

23. Belkin AM, Stepp MA. Integrins as receptors for laminins. Microsc Res Tech. (2000) 51:280-301. doi: 10.1002/1097-0029(20001101)51:3<280::AIDJEMT7>3.0.CO;2-O

24. Humphries JD, Byron A, Humphries MJ. Integrin ligands at a glance. J Cell Sci. (2006) 119:3901-3. doi: 10.1242/jcs.03098

25. Sun Z, Costell M, Fässler R. Integrin activation by talin, kindlin and mechanical forces. Nat Cell Biol. (2019) 21:25-31. doi: 10.1038/s41556-018-0234-9

26. Luo B-H, Carman C V., Springer TA. Structural basis of integrin regulation and signaling. Annu Rev Immunol. (2007) 25:619-47. doi: 10.1146/annurev.immunol.25.022106.141618

27. Alon R, Dustin ML. Force as a facilitator of integrin conformational changes during leukocyte arrest on blood vessels and antigen-presenting cells. Immunity. (2007) 26:17-27. doi: 10.1016/j.immuni.2007.01.002

28. McEver RP, Zhu C. A catch to integrin activation. Nat Immunol. (2007) 8:1035-7. doi: 10.1038/ni1007-1035

29. Chen W, Lou J, Zhu C. Forcing switch from short- to intermediateand long-lived states of the $\alpha \mathrm{A}$ domain generates LFA-1/ICAM-1 catch bonds. J Biol Chem. (2010) 285:35967-78. doi: 10.1074/jbc.M110.1 55770

30. Singh P, Carraher C, Schwarzbauer JE. Assembly of fibronectin extracellular matrix. Annu Rev Cell Dev Biol. (2010) 26:397-419. doi: 10.1146/annurev-cellbio-100109-104020

31. Horton ER, Byron A, Askari JA, Ng DHJ, Millon-Frémillon A, Robertson $J$, et al. Definition of a consensus integrin adhesome and its dynamics during adhesion complex assembly and disassembly. Nat Cell Biol. (2015) 17:1577-87. doi: 10.1038/ncb3257

32. Mitra SK, Schlaepfer DD. Integrin-regulated FAK-Src signaling in normal and cancer cells. Curr Opin Cell Biol. (2006) 18:516-23. doi: 10.1016/j.ceb.2006.08.011

33. Playford MP, Schaller MD. The interplay between Src and integrins in normal and tumor biology. Oncogene. (2004) 23:7928-46. doi: $10.1038 /$ sj.onc. 1208080 
34. Desgrosellier JS, Cheresh DA. Integrins in cancer: biological implications and therapeutic opportunities. Nat Rev Cancer. (2010) 10:9-22. doi: $10.1038 / \mathrm{nrc} 2748$

35. Dike LE, Ingber DE. Integrin-dependent induction of early growth response genes in capillary endothelial cells. J Cell Sci. (1996) 109:2855-63.

36. Zhu $\mathrm{X}$, Assoian RK. Integrin-dependent activation of MAP kinase: a link to shape-dependent cell proliferation. Mol Biol Cell. (1995) 6:273-82. doi: $10.1091 / \mathrm{mbc}$.6.3.273

37. Frisch SM, Ruoslahti E. Integrins and anoikis. Curr Opin Cell Biol. (1997) 9:701-6. doi: 10.1016/S0955-0674(97)80124-X

38. Boudreau N, Myers C, Bissell MJ. From laminin to lamin: regulation of tissue-specific gene expression by the ECM. Trends Cell Biol. (1995) 5:1-4. doi: 10.1016/S0962-8924(00)88924-2

39. Alanko J, Mai A, Jacquemet G, Schauer K, Kaukonen R, Saari M, et al. Integrin endosomal signalling suppresses anoikis. Nat Cell Biol. (2015) 17:1412-21. doi: $10.1038 /$ ncb3250

40. Matt S, Hofmann TG. The DNA damage-induced cell death response: a roadmap to kill cancer cells. Cell Mol Life Sci. (2016) 73:2829-50. doi: 10.1007/s00018-016-2130-4

41. Kaufmann SH, Earnshaw WC. Induction of apoptosis by cancer chemotherapy. Exp Cell Res. (2000) 256:42-9. doi: 10.1006/excr.2000.4838

42. Shao Y, Aplin AE. BH3-only protein silencing contributes to acquired resistance to PLX4720 in human melanoma. Cell Death Differ. (2012) 19:2029-39. doi: 10.1038/cdd.2012.94

43. Zhang Z, Vuori K, Reed JC, Ruoslahti E. The $\alpha 5 \beta 1$ integrin supports survival of cells on fibronectin and up-regulates Bcl-2 expression. Proc Natl Acad Sci USA. (1995) 92:6161-5. doi: 10.1073/pnas.92.13.6161

44. Burris HA. Overcoming acquired resistance to anticancer therapy: focus on the PI3K/AKT/mTOR pathway. Cancer Chemother Pharmacol. (2013) 71:829-42. doi: 10.1007/s00280-012-2043-3

45. Tazzari PL, Cappellini A, Ricci F, Evangelisti C, Papa V, Grafone T, et al. Multidrug resistance-associated protein 1 expression is under the control of the phosphoinositide 3 kinase/Akt signal transduction network in human acute myelogenous leukemia blasts. Leukemia. (2007) 21:427-38. doi: 10.1038/sj.leu.2404523

46. Naci D, El Azreq MA, Chetoui N, Lauden L, Sigaux F, Charron D, et al. $\alpha 2 \beta 1$ integrin promotes chemoresistance against doxorubicin in cancer cells through extracellular signal-regulated kinase (ERK). J Biol Chem. (2012) 287:17065-76. doi: 10.1074/jbc.M112.349365

47. El Azreq MA, Naci D, Aoudjit F. Collagen/ $\beta 1$ integrin signaling up-regulates the ABCC1/MRP-1 transporter in an ERK/MAPK-dependent manner. Mol Biol Cell. (2012) 23:3473-84. doi: 10.1091/mbc.e12-02-0132

48. Sarkar S, Svoboda M, De Beaumont R, Freedman AS. The role of AKT and RAFTK in $\beta 1$ integrin mediated survival of precursor bacute lymphoblastic leukemia cells. Leuk Lymphoma. (2002) 43:1663-71. doi: 10.1080/1042819021000003009

49. Astier A, Avraham H, Manie SN, Groopman J, Canty T, Avraham S, et al. The related adhesion focal tyrosine kinase is tyrosine-phosphorylated after $\beta 1$-integrin stimulation in B cells and binds to p130(cas). J Biol Chem. (1997) 272:228-32. doi: 10.1074/jbc.272.1.228

50. Berrazouane S, Boisvert M, Salti S, Mourad W, Al-Daccak R, Barabé $\mathrm{F}$, et al. Betal integrin blockade overcomes doxorubicin resistance in human T-cell acute lymphoblastic leukemia. Cell Death Dis. (2019) 10:357. doi: 10.1038/s41419-019-1593-2

51. Yu X, Zhang H, Yuan M, Zhang P, Wang Y, Zheng M, et al. Identification and characterization of a murine model of BCR-ABL1 ${ }^{+}$acute B-lymphoblastic leukemia with central nervous system metastasis. Oncol Rep. (2019) 42:52132. doi: 10.3892/or.2019.7184

52. Jiang BH, Liu LZ. Role of mTOR in anticancer drug resistance: perspectives for improved drug treatment. Drug Resist Updat. (2008) 11:63-76. doi: 10.1016/j.drup.2008.03.001

53. Dan HC, Cooper MJ, Cogswell PC, Duncan JA, Ting JPY, Baldwin AS. Akt-dependent regulation of NF- $\mathrm{B}$ is controlled by mTOR and Raptor in association with IKK. Genes Dev. (2008) 22:1490-500. doi: $10.1101 / \mathrm{gad} .1662308$

54. Zhang X, Xiao W, Wang L, Tian Z, Zhang J. Deactivation of signal transducer and activator of transcription 3 reverses chemotherapeutics resistance of leukemia cells via down-regulating P-gp. PLoS ONE. (2011) 6:e0020965 doi: 10.1371/journal.pone.0020965

55. Ozes ON, Mayo LD, Gustin JA, Pfeffer SR, Pfeffer LM, Donner DB. NF$\kappa \mathrm{B}$ activation by tumour necrosis factor requires tie Akt serine- threonine kinase. Nature. (1999) 401:82-5. doi: 10.1038/43466

56. Jacamo R, Chen Y, Wang Z, Wencai M, Zhang M, Spaeth EL, et al. Reciprocal leukemia-stroma VCAM-1/VLA-4-dependent activation of NF-кB mediates chemoresistance. Blood. (2014) 123:2691-702. doi: 10.1182/blood-2013-06-511527

57. Polak R, De Rooij B, Pieters R, Den Boer ML. B-cell precursor acute lymphoblastic leukemia cells use tunneling nanotubes to orchestrate their microenvironment. Blood. (2015) 126:2404-14. doi: 10.1182/blood-2015-03-634238

58. Pillozzi S, Bernini A, Spiga O, Lelli B, Petroni G, Bracci L, et al. Peptides and small molecules blocking the CXCR4/CXCL12 axis overcome bone marrowinduced chemoresistance in acute leukemias. Oncol Rep. (2019) 41:312-24. doi: 10.3892/or.2018.6808

59. Barrow-McGee R, Kishi N, Joffre C, Ménard L, Hervieu A, Bakhouche $\mathrm{BA}$, et al. Beta 1-integrin-c-Met cooperation reveals an inside-in survival signalling on autophagy-related endomembranes. Nat Commun. (2016) 7:11942. doi: 10.1038/ncomms11942

60. Jahangiri A, Nguyen A, Chandra A, Sidorov MK, Yagnik G, Rick J, et al. Cross-activating $c-M e t / \beta 1$ integrin complex drives metastasis and invasive resistance in cancer. Proc Natl Acad Sci USA. (2017) 114:E8685-94. doi: 10.1073/pnas.1701821114

61. Chiarini F, Lonetti A, Evangelisti C, Buontempo F, Orsini E, Evangelisti $\mathrm{C}$, et al. Advances in understanding the acute lymphoblastic leukemia bone marrow microenvironment: from biology to therapeutic targeting. Biochim Biophys Acta Mol Cell Res. (2016) 1863:449-63. doi: 10.1016/j.bbamcr.2015.08.015

62. Nilsson SK, Debatis ME, Dooner MS, Madri JA, Quesenberry PJ, Becker PS Immunofluorescence characterization of key extracellular matrix proteins in murine bone marrow in situ. J Histochem Cytochem. (1998) 46:371-7. doi: 10.1177/002215549804600311

63. Teixidó J, Hemler ME, Greenberger JS, Anklesaria P. Role of beta 1 and beta 2 integrins in the adhesion of human CD34hi stem cells to bone marrow stroma. J Clin Invest. (1992) 90:358-67. doi: 10.1172/JCI115870

64. Hirsch E, Iglesias A, Potocnik AJ, Hartmann U, Fässler R. Impaired migration but not differentiation of haematopoietic stem cells in the absence of betal integrins. Nature. (1996) 380:171-5. doi: 10.1038/380171a0

65. Potocnik AJ, Brakebusch C, Fässler R, Liver F, Marrow B, Potocnik $\mathrm{AJ}$, et al. Fetal and adult hematopoietic stem cells require $\beta 1$ integrin function for colonizing. Immunity. (2000) 12:653-63. doi: 10.1016/S1074-7613(00)80216-2

66. Gronthos S, Simmons PJ, Graves SE, G. Robey P. Integrinmediated interactions between human bone marrow stromal precursor cells and the extracellular matrix. Bone. (2001) 28:174-81. doi: 10.1016/S8756-3282(00)00424-5

67. Soligo D, Schiró R, Luksch R, Manara G, Quirici N, Parravicini C, et al. Expression of integrins in human bone marrow. Br J Haematol. (1990) 76:323-32. doi: 10.1111/j.1365-2141.1990.tb06363.x

68. Ayala F, Dewar R, Kieran M, Kalluri R. Contribution of bone microenvironment to leukemogenesis and leukemia progression. Leukemia. (2009) 23:2233-41. doi: 10.1038/leu.2009.175

69. Messinger Y, Chelstrom L, Gunther R, Uckun FM. Selective homing of human leukemic B-cell precursors to specific lymphohematopoietic microenvironments in SCID mice: a role for the $\beta 1$ integrin family surface adhesion molecules VLA-4 and VLA-5. Leuk Lymphoma. (1996) 23:61-9. doi: 10.3109/10428199609054803

70. Filshie R, Gottlieb D, Bradstock K. VLA-4 is involved in the engraftment of the human pre-B acute lymphoblastic leukaemia cell line NALM-6 in SCID mice. Br J Haematol. (1998) 102:1292-300. doi: 10.1046/j.1365-2141.1998.00899.x

71. Bendall LJ, Baraz R, Juarez J, Shen W, Bradstock KF. Defective p38 mitogenactivated protein kinase signaling impairs chemotaxic but not proliferative responses to stromal-derived factor- $1 \alpha$ in acute lymphoblastic leukemia. Cancer Res. (2005) 65:3290-8. doi: 10.1158/0008-5472.CAN-04-3402 
72. Shen W, Bendall LJ, Gottlieb DJ, Bradstock KF. The chemokine receptor CXCR4 enhances integrin-mediated in vitro adhesion and facilitates engraftment of leukemic precursor-B cells in the bone marrow. Exp Hematol. (2001) 29:1439-47. doi: 10.1016/S0301-472X(01)00741-X

73. DiGiuseppe JA, Fuller SG, Borowitz MJ. Overexpression of CD49f in precursor B-cell acute lymphoblastic leukemia: potential usefulness in minimal residualdisease detection. Cytom Part B Clin Cytom. (2009) 76:1505. doi: 10.1002/cyto.b.20440

74. Hsieh Y Te, Gang EJ, Geng H, Park E, Huantes S, Chudziak D, et al. Integrin alpha4 blockade sensitizes drug resistant pre-B acute lymphoblastic leukemia to chemotherapy. Blood. (2013) 121:1814-8. doi: 10.1182/blood-2012-01-406272

75. Shalapour S, Hof J, Kirschner-Schwabe R, Bastian L, Eckert C, Prada J, et al. High VLA-4 expression is associated with adverse outcome and distinct gene expression changes in childhood B-cell precursor acute lymphoblastic leukemia at first relapse. Haematologica. (2011) 96:1627-35. doi: 10.3324/haematol.2011.047993

76. Blenc AM, Chiagev A, Sklar L, Larson RS. VLA-4 affinity correlates with peripheral blood white cell count and DNA content in patients with precursor B-ALL [4]. Leukemia. (2003) 17:641-3. doi: 10.1038/sj.leu.24 02827

77. Hu Z, Slayton WB. Integrin VLA-5 and FAK are good targets to improve treatment response in the Philadelphia chromosome positive acute lymphoblastic leukemia. Front Oncol. (2014) 4:112. doi: 10.3389/fonc.2014.00112

78. Castro F V., McGinn OJ, Krishnan S, Marinov G, Li J, Rutkowski AJ, et al. 5T4 oncofetal antigen is expressed in high risk of relapse childhood pre-B acute lymphoblastic leukemia and is associated with a more invasive and chemotactic phenotype. Leukemia. (2012) 26:1487-98. doi: 10.1038/leu.2012.18

79. Scharff BFSS, Modvig S, Thastrup M, Levinsen M, Degn M, Ryder LP, et al. A comprehensive clinical study of integrins in acute lymphoblastic leukemia indicates a role of $\alpha 6 / \mathrm{CD} 49 \mathrm{f}$ in persistent minimal residual disease and $\alpha 5$ in the colonization of cerebrospinal fluid. Leuk Lymphoma. (2020) 0:1-5. doi: 10.1080/10428194.2020.1731500

80. Kondoh T, Kuribayashi K, Tanaka M, Kobayashi D, Yanagihara N, Watanabe N. CD7 promotes extramedullary involvement of the B-cell acute lymphoblastic leukemia line Tanoue by enhancing integrin $\beta 2$-dependent cell adhesiveness. Int J Oncol. (2014) 45:1073-81. doi: 10.3892/ijo.2014. 2492

81. Gaynes JS, Jonart LM, Zamora EA, Naumann JA, Gossai NP, Gordon PM. The central nervous system microenvironment influences the leukemia transcriptome and enhances leukemia chemo-resistance. Haematologica. (2017) 102:e136-9. doi: 10.3324/haematol.2016.152926

82. Jonart LM, Ebadi M, Basile P, Johnson K, Makori J, Gordon PM. Disrupting the leukemia niche in the central nervous system attenuates leukemia chemoresistance. Haematologica. (2019). doi: 10.3324/haematol.2019.230334. [Epub ahead of print].

83. Murti KG, Brown PS, Kumagai MA, Campana D. Molecular interactions between human B-cell progenitors and the bone marrow microenvironment. Exp Cell Res. (1996) 226:47-58. doi: 10.1006/excr.1996.0201

84. Winter SS, Sweatman JJ, Lawrence MB, Rhoades TH, Hart AL, Larson RS. Enhanced T-lineage acute lymphoblastic leukaemia cell survival on bone marrow stroma requires involvement of LFA-1 and ICAM1. Br J Haematol. (2001) 115:862-71. doi: 10.1046/j.1365-2141.2001. 03182.x

85. Lichterfeld M, Martin S, Burkly L, Haas R, Kronenwett R. Mobilization of $\mathrm{CD}^{+} 4^{+}$haematopoietic stem cells is associated with a functional inactivation of the integrin very late antigen 4. Br J Haematol. (2000) 110:71-81. doi: 10.1046/j.1365-2141.2000.02130.x

86. Locker GJ, Stoiser B, Losert H, Wenzel C, Ohler L, Kabrna E, et al. Decrease of circulating hematopoietic progenitor cells During interleukin-2 treatment is associated with an increase of vascular cell adhesion molecule-1, a critical molecule for progenitor cell adhesion. Leuk Lymphoma. (2000) 39:355-64. doi: 10.3109/10428190009065835

87. Hsieh YT, Gang EJ, Shishido SN, Kim HN, Pham J, Khazal S, et al. Effects of the small-molecule inhibitor of integrin $\alpha 4$, TBC3486, on pre-B-ALL cells. Leukemia. (2014) 28:2101-4. doi: 10.1038/leu.2014.182
88. Sharif Y, Jumah F, Coplan L, Krosser A, Sharif K, Tubbs RS. Blood brain barrier: a review of its anatomy and physiology in health and disease. Clin Anat. (2018) 31:812-23. doi: 10.1002/ca.23083

89. Ghersi-Egea JF, Strazielle N, Catala M, Silva-Vargas V, Doetsch F, Engelhardt B. Molecular anatomy and functions of the choroidal blood-cerebrospinal fluid barrier in health and disease. Acta Neuropathol. (2018) 135:337-61. doi: 10.1007/s00401-018-1807-1

90. Kivisäkk P, Mahad DJ, Callahan MK, Trebst C, Tucky B, Wei T, et al. Human cerebrospinal fluid central memory $\mathrm{CD} 4^{+} \mathrm{T}$ cells: evidence for trafficking through choroid plexus and meninges via P-selectin. Proc Natl Acad Sci USA. (2003) 100:8389-94. doi: 10.1073/pnas.1433000100

91. Ransohoff RM, Engelhardt B. The anatomical and cellular basis of immune surveillance in the central nervous system. Nat Rev Immunol. (2012) 12:62335. doi: $10.1038 /$ nri3265

92. Wilson EH, Weninger W, Hunter CA. Trafficking of immune cells in the central nervous system. J Clin Invest. (2010) 120:1368-79. doi: 10.1172/JCI41911

93. Stüve O, Marra CM, Bar-Or A, Niino M, Cravens PD, Cepok S, et al. Altered $\mathrm{CD} 4^{+} / \mathrm{CD}^{+}$T-cell ratios in cerebrospinal fluid of natalizumabtreated patients with multiple sclerosis. Arch Neurol. (2006) 63:1383-7. doi: 10.1001/archneur.63.10.1383

94. Polman CH, O’Connor PW, Havrdova E, Hutchinson M, Kappos L, Miller $\mathrm{DH}$, et al. A randomized, placebo-controlled trial of natalizumab for relapsing multiple sclerosis. N Engl J Med. (2006) 354:899-910. doi: 10.1056/NEJMoa044397

95. Steffen BJ, Breier G, Butcher EC, Schulz M, Engelhardt B. ICAM-1, VCAM1, and MAdCAM-1 are expressed on choroid plexus epithelium but not endothelium and mediate binding of lymphocytes in vitro. Am J Pathol. (1996) 148:1819-38.

96. Wolburg K, Gerhardt H, Schulz M, Wolburg H, Engelhardt B. Ultrastructural localization of adhesion molecules in the healthy and inflamed choroid plexus of the mouse. Cell Tissue Res. (1999) 296:259-69. doi: $10.1007 /$ s004410051287

97. Price RA, Johnson WW. The central nervous system in childhood leukemia: I. The arachnoid. Cancer. (1973) 31:520-33. doi: 10.1002/10970142(197303)31:3<520::AID-CNCR2820310306>3.0.CO;2-2

98. Strazielle N, Creidy R, Malcus C, Boucraut J, Ghersi-Egea J-F. T-lymphocytes traffic into the brain across the blood-CSF barrier: evidence using a reconstituted choroid plexus epithelium. PLoS ONE. (2016) 11:e0150945. doi: 10.1371/journal.pone.0150945

99. März M, Meyer S, Erb U, Georgikou C, Horstmann MA, Hetjens S, et al. Pediatric acute lymphoblastic leukemia-conquering the CNS across the choroid plexus. Leuk Res. (2018) 71:47-54. doi: 10.1016/j.leukres.2018.0 7.001

100. Naumann JA, Gordon PM. In vitro model of leukemia cell migration across the blood-cerebrospinal fluid barrier. Leuk Lymphoma. (2017) 58:1747-9. doi: 10.1080/10428194.2016.1254778

101. Akers SM, O’Leary HA, Minnear FL, Craig MD, Vos JA, Coad JE, et al. VE-cadherin and PECAM-1 enhance ALL migration across brain microvascular endothelial cell monolayers. Exp Hematol. (2010) 38:733-43. doi: 10.1016/j.exphem.2010.05.001

102. Kinjyo I, Bragin D, Grattan R, Winter SS, Wilson BS. Leukemia-derived exosomes and cytokines pave the way for entry into the brain. J Leukoc Biol. (2019) 105:741-53. doi: 10.1002/JLB.3A0218-054R

103. Gust J, Hay KA, Hanafi LA, Li D, Myerson D, Gonzalez-Cuyar LF, et al. Endothelial activation and blood-brain barrier disruption in neurotoxicity after adoptive immunotherapy with CD19 CAR-T cells. Cancer Discov. (2017) 7:1404-19. doi: 10.1158/2159-8290.CD-17-0698

104. Hara J, Matsuda Y, Fujisaki H, Tokimasa S, Ohta H, Osagi Y, et al. Expression of adhesion molecules in childhood B-lineage-cell neoplasms. Int J Hematol. (2000) 72:69-73.

105. Rosenman SJ, Dubb L, Shrikant P, Benveniste EN, Ransohoff RM. Cytokineinduced expression of vascular cell adhesion molecule-1 (VCAM-1) by astrocytes and astrocytoma cell lines. J Immunol. (1995) 154:1888-99.

106. Bovetti S, Hsieh YC, Bovolin P, Perroteau I, Kazunori T, Puche AC. Blood vessels form a scaffold for neuroblast migration in the adult olfactory bulb. J Neurosci. (2007) 27:5976-80. doi: 10.1523/JNEUROSCI.0678-0 7.2007 
107. Flanagan LA, Rebaza LM, Derzic S, Schwartz PH, Monuki ES. Regulation of human neural precursor cells by laminin and integrins. J Neurosci Res. (2006) 83:845-56. doi: 10.1002/jnr.20778

108. Akers SM, Rellick SL, Fortney JE, Gibson LF. Cellular elements of the subarachnoid space promote ALL survival during chemotherapy. Leuk Res. (2011) 35:705-11. doi: 10.1016/j.leukres.2010.12.031

109. Ley K, Rivera-Nieves J, Sandborn WJ, Shattil S. Integrin-based therapeutics: biological basis, clinical use and new drugs. Nat Rev Drug Discov. (2016) 15:173-83. doi: 10.1038/nrd.2015.10

110. Sison EAR, Kurre P, Kim YM. Understanding the bone marrow microenvironment in hematologic malignancies: a focus on chemokine, integrin, and extracellular vesicle signaling. Pediatr Hematol Oncol. (2017) 34:365-78. doi: 10.1080/08880018.2017.1395938

111. Herisson F, Frodermann V, Courties G, Rohde D, Sun Y, Vandoorne K, et al. Direct vascular channels connect skull bone marrow and the brain surface enabling myeloid cell migration. Nat Neurosci. (2018) 21:1209-17. doi: 10.1038/s41593-018-0213-2

112. Jost TR, Borga C, Radaelli E, Romagnani A, Perruzza L, Omodho L, et al. Role of CXCR4-mediated bone marrow colonization in CNS infiltration by T cell acute lymphoblastic leukemia. J Leukoc Biol. (2016) 99:1077-87. doi: 10.1189/jlb.5MA0915-394R

113. Cao W, Liang C, Gen Y, Wang C, Zhao C, Sun L. Role of diffusion-weighted imaging for detecting bone marrow infiltration in skull in children with acute lymphoblastic leukemia. Diagn Interv Radiol. (2016) 22:580-6. doi: 10.5152/dir.2016. 15167

Conflict of Interest: The authors declare that the research was conducted in the absence of any commercial or financial relationships that could be construed as a potential conflict of interest.

Copyright $\odot 2020$ Scharff, Modvig, Marquart and Christensen. This is an open-access article distributed under the terms of the Creative Commons Attribution License (CC $B Y)$. The use, distribution or reproduction in other forums is permitted, provided the original author(s) and the copyright owner(s) are credited and that the original publication in this journal is cited, in accordance with accepted academic practice. No use, distribution or reproduction is permitted which does not comply with these terms. 